\title{
The Simple Analytics of Elite Behaviour Under Limited State Capacity
}

\author{
François Bourguignon, ${ }^{1}$ and \\ Thierry Verdier ${ }^{2}$
}

September 2010

\begin{abstract}
This paper discusses the issue of taxation and redistribution in economies dominated by Elites with limited state capacity. Within a simple aggregate framework, we discuss the political economy incentives of Elites to tax, redistribute and increase state capacity. In particular, the analysis highlights the role of complementarities or substitutability in the production process between the factors controlled by the Elite and other social groups and shows the existence of natural increasing returns for Elites to increase state capacity. The paper also discusses how the incentives for state capacity building are affected by political threats of power shifting.
\end{abstract}

Keywords: Elites, redistribution, political economy, state capacity building

JEL classification: Z13

\section{Copyright (C) UNU-WIDER 2010}

1 Paris School of Economics, France. E-mail: francois.bourguignon@parisschoolofeconomics.edu 2 Paris-Jourdan Sciences Économiques, France. E-mail: verdier@pse.ens.fr

This study has been prepared within the UNU-WIDER project on The Role of Elites in Economic Development, directed by Alice Amsden, James Robinson, and Alisa DiCaprio.

UNU-WIDER gratefully acknowledges the financial contributions to the research programme by the governments of Denmark (Royal Ministry of Foreign Affairs), Finland (Ministry for Foreign Affairs), Sweden (Swedish International Development Cooperation Agency-Sida) and the United Kingdom (Department for International Development-DFID). 
The World Institute for Development Economics Research (WIDER) was established by the United Nations University (UNU) as its first research and training centre and started work in Helsinki, Finland in 1985. The Institute undertakes applied research and policy analysis on structural changes affecting the developing and transitional economies, provides a forum for the advocacy of policies leading to robust, equitable and environmentally sustainable growth, and promotes capacity strengthening and training in the field of economic and social policy making. Work is carried out by staff researchers and visiting scholars in Helsinki and through networks of collaborating scholars and institutions around the world.

www.wider.unu.edu publications@wider.unu.edu

UNU World Institute for Development Economics Research (UNU-WIDER)

Katajanokanlaituri 6 B, 00160 Helsinki, Finland

Typescript prepared by the Authors.

The views expressed in this publication are those of the author(s). Publication does not imply endorsement by the Institute or the United Nations University, nor by the programme/project sponsors, of any of the views expressed. 


\title{
The Simple Analytics of Elite Behavior under Limited State Capacity*
}

\author{
François Bourguignon (PSE) \\ Thierry Verdier (PSE and CEPR)
}

June 16, 2010

\begin{abstract}
This paper discusses the issue of taxation and redistribution in economies dominated by Elites with limited state capacity. Within an a simple aggregate framework, we discuss the political economy incentives of Elites to tax, redistribute and increase state capacity. In particular, the analysis highlights the role of complementarities or substituabilities in the production process between the factors controled by the Elite and other social groups and shows the existence of natural increasing returns for Elites to increase state capacity. The paper also discusses how the incentives for state capacity building are affected by political threats of power shifting.

Key words: Elites, redistribution, political economy, state capacity building.
\end{abstract}

\section{Introduction}

Economists are everyday more convinced that institutions and institutional change play a crucial role in development. There is rather strong evidence of this, based on history or on cross-country comparisons - see for instance Amsden (2001), Vu (2007), Keefer and Knack (1995), Olson et al. (2000), Acemoglu et al. (2002) or Rodrik et al. (2004). ${ }^{1}$ Yet, this literature has mostly focused on the causality relationship that goes from institutions to development. Even though it is fully recognized in the literature on institutions and development that institutions are endogenous to the development process, institutional change is rarely explicitly taken into account. By contrast, the recent literature on the

\footnotetext{
*This paper has been written for the WIDER conference on "Elites and Economic Development" held in Helsinki 12-13 June 2009. We thank Elise Brezis, the participants of the conference and three anonymous referees for useful comments and suggestions. All errors remain ours.

${ }^{1}$ But see also Glaeser et al. (2004) for a contrarian view and Collier (1979), O'Donnell (1979), Evans, Rueschemeyer, and Skocpol (1985), Amsden (2001), Vu (2010) for alternative historical and case study approaches.
} 
political economy of development is precisely about endogenizing institutional change, or, of course, persistence.

Among the various elements that trigger institutional change, an important one relates to the behavior of elites and their incentives to permit and invest in such a change (Hossain et al. 1999). A well defined research perspective in Economic History has focused on this issue (Brezis and Temin (1999), Crouzet and Brezis (2006), Brezis (2010)). More formally, papers such as Acemoglu and Robinson $(2005,2006,2008)$ tend to concentrate on the change of political regime - and in particular the switch to democracy or the persistence of elite control.

Another important part of the recent theoretical development literature is concerned with economic rather than political institutions. It focuses in particular on the issue of 'fiscal and administrative state capacity', that is the capacity of a state to actually 'govern' the economy through levying taxes and spending efficiently the proceeds on specific public goods, guaranteeing property rights or regulating the activity of the private sector. Some theoretical political economy models rely on this concept of state capacity to represent the behavior of the elite in extracting rents from the whole economy while at the same time trying to keep control for political power - see in particular Acemoglu (2006). Empirically, several papers have tried to unbundle the role of economic institutions in economic development and have implicitly shown the importance of state capacity for the quality of institutions (see for instance Acemoglu and Johnson (2005), Rodrik et al. (2004), Djankov, McLiesh and Ramalho (2006))..

Somewhat surprisingly, however, few papers tried to go further and to explore the determinants of state capacity. Two recent exceptions however are Besley and Persson (2008, 2009). Within a simple but ingenuous analytical framework, these papers study the incentives of the elite in political control to invest in various dimensions of state capacity. They show in particular how economic development, political stability, or the polarization of society contribute to more or less investments in fiscal and administrative capacity by the group in political control.

The present piece of work also focuses on the determinants of state capacity in societies where the elite tries to extract as much rent as it can from the economy while trying to minimize the probability of losing political power. However, the emphasis is put here on the structure of the economy where the elite is operating and its implications for the level of taxation, economic efficiency and state capacity building. Two features prove important from that point of view. First, it matters whether the economy is ruled by a 'political elite' without a direct involvement in economic activity, or whether it is ruled by a 'business elite' which has the ability to extract rents but with a direct involvement in economic activity. Second, it is shown that, the behavior of a 'business elite' and its incentives to build state capacity depend very much on the extent to which the productive assets it owns are complements or substitutes of the other productive factors owned by other groups. ${ }^{2}$

\footnotetext{
${ }^{2}$ As a first pass, our analysis assumes that groups are homogeneous. This allows us to
} 
In particular, our analysis provides a typology of different economic structures with different implications for the redistributive behavior of the elite and its incentives to invest in state capacity. Such distinctions are important as it should contribute to a better understanding of why different elitedominated societies may behave in quite different ways. For instance, elitedominated economies relying primarily on mineral natural resources are likely to behave differently than elite-dominated economies relying on manufacturing exports. Indeed the nature of their productive interdependencies with other social groups will be different, inducing therefore different incentives for redistribution and state building capacities.

The paper is organized as follows. In section 2, we start with a simple 2-factor capital-labor model where the elite owns the non-labor factor of production. We assume that the elite can use an instrument (a tax rate) to extract rents from the non elite group (i.e. workers). Workers can also work in an informal sector which escapes taxation. This feature limits therefore the ability of the elite to extract rents from them either directly, through taxes, or indirectly through changes in factor prices, for a given level of state capacity. We derive in such a context the extent of redistribution that the elite can achieve in its own favor. Fiscal state capacity appears as a key parameter of this simple model. We then discuss therefore the incentives for state capacity building and show that the elite intends either to maintain this capacity at a minimum or to expand it at a maximum.

Section 3 discusses the possibility of political power shifting. Indeed, another limitation to the predation exerted by the elite comes from the risk to lose power, especially if it were to reduce too much the welfare of workers in comparison with what they would be able to secure for themselves if they were in power. In that case, the elite faces the possibility that the state capacity it built would be used by the new rulers against them. This reduces the incentives to invest in state capacity when the full political economy equilibrium is considered.

Section 4 is devoted to the important case where there is separability between the factor owned by the elite and the others in the aggregate production function of the economy. The elite can then be considered as purely 'political' in the sense that what it decides about taxation of labor has no impact on the return of its own asset. Such a situation is consistent for instance with an elite that derives income from the control of natural resources that are exported. This is a situation commonly observed in many developing countries with non-democratic regimes.

Section 5 goes beyond the 2-class model and extends the framework to the case where there is an additional factor that is not owned by the elite in power. This leads to a 3 factors/ 3 classes structure which provides a typology of plausible situations observed today in developing countries. Key in that typology is the degree of substitutability or complementarity between the assets owned

distinguish in a simple way the behavior of those in power (elite groups) from those out of power. Doing so however abstracts from the important issue of intra-group heterogeneity and its implications for elite behaviors. 
by the elite and the assets owned by the other classes. More specifically, the analysis focuses on whether the asset owned by the elite is a substitute or a complement to the assets owned by the other classes. In those various situations, the intensity and the structure of predation by the elite turns out to be different. This is also true of the incentives to develop state capacity.

The last section of the paper draws together the various results obtained in the paper, and concludes with some suggestions for future research.

\section{A simple 2-factor/2-class model of elite dom- ination}

\subsection{Production structure}

The economy comprises two groups of agents. In each group, each member owns some asset that contributes to production. More specifically, the elite $E$ has $\bar{K}_{E}$ members, each one owning one unit of a specific asset $K_{E}$. Similarly, each member of the working class $L$ of size $\bar{L}$, owns one unit of labor.

There is one numeraire good produced and consumed under competitive conditions. This good can be produced in two ways. First, it can be produced in the formal sector of the economy (that is eventually subject to taxation) according to a standard neoclassical constant-return-to-scale concave technology $Q=G\left(K_{E}, L\right)$ with $K_{E}$ and $L$ respectively the amount of specific assets owned by class $E$ and labor $L$ used for production in that sector. This formal sector is assumed to be competitive so that the gross marginal returns of the productive factors are simply given by the partial derivatives: $G_{E}^{\prime}\left(K_{E}, L\right)$ and $G_{L}^{\prime}\left(K_{E}, L\right)$. Because of the concavity and homogeneity of the production function, these marginal returns are decreasing (ie. $G_{E E}^{\prime \prime}<0$ and $G_{L L}^{\prime \prime}<0$ ) and $K_{E}$ and $L$ are complements (ie. $G_{E L}^{\prime \prime}>0$ ).

Second, the numeraire good can also be produced by workers in an informal/subsistence sector that escapes taxation ${ }^{3}$. We assume that the size $L_{\text {inf }}$ of this informal sector is a decreasing function of the after-tax wage $w$ obtained in the formal economy $L_{\text {inf }}=L_{\text {inf }}(w)$ with some boundary conditions: $L_{\text {inf }}(0)=\bar{L}$ and $L_{\text {inf }}(\bar{w})=0$ for some $\bar{w}$. The labor supply to the formal sector writes therefore as $L=\bar{L}-L_{\inf }(w)=L^{S}(w)$ with $L^{S}(w)$ an increasing function of $w$. This feature of the economy clearly limits the capacity of the elite to extract rents from workers.

In the sequel, it will be more convenient to use the inverse labor supply function $w=L^{S^{-1}}(L)=w^{S}(L)$ with $w^{S}(L)$ an increasing function of $L$ with $w^{S}(0)=0$ and $w^{S}(\bar{L})=\bar{w}$.

\footnotetext{
${ }^{3}$ In general informal sector workers cannot fully evade effective taxation as they may still be subject to consumption taxes and the inflation tax, the extent of which depends on the composition of their consumption bundle between formal sector and informal-sector goods. While these elements do introduce some interesting features, what is important for our discussion is simply the fact that individuals in the informal economy are relatively less "taxable" than individuals working in the formal sector.
} 


\subsection{Taxation and distribution}

We assume that the elite extracts a rent from the working class through a tax levied on labor income in the formal sector. More precisely, given $\tau_{L} \in[0,1]$ the tax rate imposed on workers, we assume that the elite can extract rents from the formal sector equal to $T=\phi \tau_{L} G_{L}^{\prime} L$ where $\phi \in[0,1]$ denotes the redistributive efficiency of the government, or the 'state capacity' of the economy. As in Acemoglu (2006), $1-\phi$ is defined as a 'leakage' that is taking place in the taxation system. State capacity is thus the capacity of the government to avoid such a leakage. Various interpretations of this parameter can be given. It may reflect first the inefficiency of bureaucrats in charge of levying taxes and chanelling its proceeds. Second, $T$ can be interpreted as a public good specific to the elite, in which case $1-\phi$ may be seen as the inefficiency in producing that good. Finally, $1-\phi$ may also describe the degree of corruption of bureaucrats, although we do not take into account the corresponding revenues here ${ }^{4}$.

\subsection{Economic equilibrium}

The demand for factor $K_{E}$ is simply given by the competitive condition

$$
G_{E}^{\prime}\left(\bar{K}_{E}, L\right)=r_{E}
$$

which says that the marginal productivity of asset $K_{E}$ is just the net return, $r_{E}$, on that asset. Given that the supply of elite capital is inelastic at $K_{E}=\bar{K}_{E}$, equation (1) gives the unit return to the asset owned by each elite member, as a function of the number of workers $L$ employed in the formal sector of the economy. In our framework, it is this dependence (i.e. $G_{E L}^{\prime \prime}>0$ ) that makes the elite a "business elite".

Similarly, the after tax wage $w$ obtained by a worker in the formal sector is given by

$$
\left(1-\tau_{L}\right) G_{L}^{\prime}\left(\bar{K}_{E}, L\right)=w
$$

where $\tau_{L}$ is the rate of taxation of labor, w being the earnings net of taxes. Combining supply and demand, the equilibrium on the formal labor market writes as ${ }^{5}$ :

$$
\left(1-\tau_{L}\right) G_{L}^{\prime}\left(\bar{K}_{E}, L\right)=w^{S}(L)
$$

The solution of (2) gives an allocation $L=L\left(\tau_{L}\right)$ trivially decreasing in $\tau_{L}$. Hence there is a univoque correspondence between the equilibrium level

\footnotetext{
${ }^{4}$ Note that we do not explicitly take into account the fact that bureaucrats are workers who have opted for the formal sector. This is justified if bureaucratic employment represents a small proportion of total employment. Another way of defining state capacity would be via the control the State may have on informal activities, i.e. the function $L_{\text {inf }}($.$) introduced$ above. This is the approach followed by Besley and Persson (2007).

${ }^{5}$ The following assumptions ensure that (2) has a unique interior solution $L \in[0, \bar{L}[$

$$
G_{L}^{\prime}\left(\bar{K}_{E}, 0\right)=+\infty, \quad \bar{w}>G_{L}^{\prime}\left(\bar{K}_{E}, \bar{L}\right)
$$
}


$L$ and the tax rate $\tau_{L}$. We shall use extensively that relationship and work primarily with employment, $L$, rather than the tax rate $\tau_{L}$. This implies some constraints on $L$. Of course, $\tau_{L}=1-w^{S}(L) / G_{L}^{\prime}\left(\bar{K}_{E}, L\right)$ has to be in the interval $[0,1]^{6}$, which is equivalent to the equilibrium labor force $L$ satisfying : $G_{L}^{\prime}\left(\bar{K}_{E}, L\right)-w^{S}(L) \geq 0$ and $L \geq 0$. Denote then by $L^{0}$ the solution of $G_{L}^{\prime}\left(\bar{K}_{E}, L\right)-w^{S}(L)=0$, namely the equilibrium allocation of labor in the formal sector when there is no taxation (ie. $\tau_{L}=0$ ). The implementable set of equilibrium formal employment is simply reduced to the segment $\left[0, L^{0}\right]$.

\subsection{Behavior of the Elite without power shifting}

Assume that the elite wants to maximize the average income of its members. The objective function of the elite is then given by:

$$
W_{E}=G_{E}^{\prime}\left(\bar{K}_{E}, L\right) \bar{K}_{E}+\phi \tau_{L} G_{L}^{\prime}\left(\bar{K}_{E}, L\right) \cdot L
$$

Taking into account the equilibrium condition $\left(1-\tau_{L}\right) G_{L}^{\prime}\left(\bar{K}_{E}, L\right)=w^{S}(L)$, one can write the maximization problem of the elite in terms of allocations $L$ as:

$$
\underset{L \in\left[0, L^{0}\right]}{\operatorname{Max}} \widehat{W}_{E}(L)=G_{E}^{\prime}\left(\bar{K}_{E}, L\right) \bar{K}_{E}+\phi R\left(\bar{K}_{E}, L\right)
$$

with

$$
R\left(\bar{K}_{E}, L\right)=\tau_{L} G_{L}^{\prime}\left(\bar{K}_{E}, L\right) \cdot L=\left[G_{L}^{\prime}\left(\bar{K}_{E}, L\right)-w^{S}(L)\right] L
$$

The first term of the maximand reflects the "market income" generated by asset $\bar{K}_{E}$ in the formal sector of the economy. The second term $\phi R\left(\bar{K}_{E}, L\right)$ is the rent that the elite extracts from taxing labor.

The two sources of income for the elite are easily represented in figure 1. The first quadrant 1a) represents the "market income" $G_{E}^{\prime}\left(\bar{K}_{E}, L\right) \bar{K}_{E}$ of the elite as a function of $L$. It is increasing in $L$, reflecting the complementarity between the elite's asset and formal labor $L$. The second quadrant $1 \mathrm{~b}$ ) shows the " tax income" $R\left(\bar{K}_{E}, L\right)$ of the elite. It has the typical Laffer curve shape. At $L=0$ (i.e. no tax base) and $L=L_{0}$ (ie. $\tau_{L}=0$ and no tax rate), this "rent income" is equal to zero. It has a maximum at some intermediate level $L=L_{f}$. Obviously at $L=L_{0}$ the slope $R_{L}^{\prime}\left(\bar{K}_{E}, L_{0}\right)$ is negative.

\section{- Equilibrium taxation by the elite}

The equilibrium of the elite-dominated economy is then obtained by maximizing $\widehat{W}_{E}(L)$, which is a linear combination of the market or "business" income of the elite and the tax income functions.

Clearly, the elite is not going to tax workers as long as

$$
\left(\frac{\partial \widehat{W}_{E}}{\partial L}\right)_{L=L_{0}}>0
$$

\footnotetext{
${ }^{6}$ Note that we are ruling out the possibility for the elite to subsidize formal labor.
} 
This condition is equivalent to

$$
\phi \leq \phi_{0}=-\left(\frac{G_{E L}^{\prime \prime} \bar{K}_{E}}{R_{L}^{\prime}}\right)_{L=L_{0}}
$$

where the arguments of the $G_{E L}^{\prime \prime}$ and $R_{L}^{\prime}$ functions have been dropped for simplicity.

Conversely, when $\phi \geq \phi_{0}$, the optimal formal labor allocation is the solution to the first order condition ${ }^{7}$ :

$$
\frac{\partial \widehat{W}_{E}}{\partial L}=G_{E L}^{\prime \prime} \bar{K}_{E}+\phi R_{L}^{\prime}=0
$$

This equation provides a solution $L(\phi)$ which is a decreasing function of state capacity $\phi^{8}$. Note that $L(\phi)$ is necessarily larger than the "Laffer curve" level $L_{f}$ that maximizes the elite tax income $R\left(\bar{K}_{E}, L\right)$. At that point in figure $1 \mathrm{~b}, R_{L}^{\prime}$ is equal to zero whereas the first term on the RHS of (4) is positive. Therefore, the elite does not benefit from reducing employment so much through such heavy taxation of labor.

This discussion can be summarized in the following way:

- Assume that the function $\widehat{W}_{E}(L)$ is well defined and concave in L. Then there exists a threshold value of state capacity $\left.\phi_{0} \in\right] 0,1[$ such that i) For $\phi \leq \phi_{0}$, the elite does not tax workers (i.e. $\tau_{L}=0$ and $\left.L=L_{0}\right)$; ii) For $\phi>\phi_{0}$, the elite taxes workers. The optimal value $L(\phi)$ (respectively $\left.\tau_{L}(\phi)\right)$ is decreasing (resp. increasing) in $\phi$.

The intuition of these results is rather simple and illustrated with the help of figure 1. As said, the objective of the elite is a linear combination of its "market income" and the 'tax income" it can extract from workers. The "market income" reflects the "business" interests of the elite. As seen in figure 1a) it would induce the elite to maximize the return on its own asset with a maximum value of formal labor $L^{0}$ and zero tax on labor income ${ }^{9}$. At the same time though, the elite can also extract rents from workers through taxation. As illustrated in figure $1 \mathrm{~b}$ ), this motive would ideally lead to reduce formal employment to the "Laffer curve" maximizing level $L_{f}$,. The cost of such a choice however

\footnotetext{
${ }^{7}$ To get a well defined maximization problem, we assume that the two elite income functions $G_{E}^{\prime}\left(\bar{K}_{E}, L\right) \bar{K}_{E}$ and $\phi R\left(\bar{K}_{E}, L\right)$ are strictly concave in $L$ so that $\widehat{W}_{E}(L)$ is also strictly concave in $L$. This is satisfied when $G^{\prime \prime \prime}{ }_{E L L}<0$ and $\left[G^{\prime \prime}{ }_{L L L}-\left(w^{S}\right) "(L)\right]+G^{\prime}{ }_{L L}-\left(w^{S}\right)^{\prime}(L)<0$. ${ }^{8}$ Differentiation of (4) gives immediately

$$
L^{\prime}(\phi)=-\frac{R_{L}^{\prime}}{\frac{\partial^{2} \widehat{W}_{E}}{\partial L^{2}}}=\frac{G_{E L}^{\prime \prime} \bar{K}_{E}}{\phi \frac{\partial^{2} \widehat{W}_{E}}{\partial L^{2}}}<0
$$

${ }^{9}$ In effect, it might even be willing to subsidize work in the formal sector, up to certain limit, if this were possible.
} 
would be to reduce the return on the elite's asset. When state capacity is low - below $\phi_{0}-$ the "rent extraction" motive is not strong enough to induce the Elite to tax workers. Indeed, the elite would get too little from rent-seeking in comparison with what it loses on the return of its asset. The optimal tax rate therefore is zero. When state capacity increases however, rent-seeking becomes more attractive and the elite combines its two sources of revenues: return on its asset and rent extraction from the workers class. It picks up a optimal level $L(\phi) \geqslant L_{f}$ that trade-offs the two sources of income.

While intuitive, the result that below a certain threshold $\phi_{0}$, the elite does not tax workers may appear extreme and unrealistic. Indeed it rests on the implicit assumption that there is zero (negligible) cost to run the state apparatus. In reality, there is certainly a minimum incompressible amount of fiscal revenue that a government needs to assume basic administrative or military state functions. Then the analysis would have to be amended and should include a minimal public revenue constraint that needs to be satisfied by the elite in problem (3). In that case, it is easy to see that for $\phi \leq \phi_{0}$, the elite will pick up the minimal tax rate on workers compatible with the minimal public revenue constraint.

\section{- Elite's Incentives to build state capacity}

What are the incentives of the elite in building state capacity in this economy? One can see that by looking at how the maximized value $\widehat{W}_{E}^{E}(\phi)$ of the elite

$$
\widehat{W}_{E}^{E}(\phi)=\operatorname{Max}_{L \in\left[0, L^{0}\right]} \widehat{W}_{E}(L)
$$

depends on $\phi$. Obviously when $\phi \leq \phi_{0}$, the elite does not tax workers and $\widehat{W}_{E}^{E}(\phi)$ is independent from $\phi$. For $\phi \geq \phi_{0}$, differentiation of $\widehat{W}_{E}^{E}(\phi)$ provides immediately

$$
\frac{d \widehat{W}_{E}^{E}}{d \phi}=R\left(\bar{K}_{E}, L(\phi)\right)>0 \text { and } \frac{d^{2} \widehat{W}_{E}^{E}}{d \phi^{2}}=R_{L}^{\prime}\left(\bar{K}_{E}, L(\phi)\right) L^{\prime}(\phi)>0
$$

Typically, the elite cannot be worse off when state capacity increases since either it does not tax labor or it does so and its revenue rises with state capacity.

The convexity of the objective function of the elite, $\widehat{W}_{E}^{E}$, for $\phi \geq \phi_{0}$ can be explained in the following way. When state capacity increases, the elite is getting more revenue from the rent it extracts from workers at a given tax rate. The increase in revenue it gets from an increase in state capacity is in effect proportional to the proceeds of the tax on labor At the same time, the elite increases the tax rate. Employment goes down but because optimal employment always lies in the downward sloping part of the Laffer curve in Figure 1.b, tax revenues increase. Hence the total income of the elite is a convex function of state capacity. Note that these "natural" increasing returns to scale in state capacity building are independent from any fixed cost to build 
up fiscal infrastructures. It entirely comes from the increased elite incentives to extract more rent when state capacity increases.

Thinking in terms of state capacity building, the implication of the convexity property is important. Consider for instance a situation with an initial level of state capacity $\phi$ and assume that there is a cost for the elite to improve that level by some increment $\Delta \phi$ and this cost is proportional to $\Delta \phi$, with a marginal cost equal to $\alpha$. As shown in figure $2 \mathrm{a}$ ), the convexity of the objective function implies that there are two strategies in terms of state capacity building. For a given marginal cost of investment in state capacity, there exists a threshold $\phi^{*}$ such that the elite will not have any marginal incentive to build further state capacity below that threshold, or on the contrary will develop maximum state capacity (ie. $\phi+\Delta \phi=1$ ) above that threshold. Of course, the threshold $\phi^{*}$ is necessarily above the threshold $\phi_{0}$ below which the elite does not tax labor.

An important dynamic property of this model is that the business elite has no incentive to build state capacity if it starts from a limited capacity - it would actually destroy capacity if it could. This can be seen in figure $2 \mathrm{~b}$ ) which plots the function $\widehat{W}_{E}^{E}(\phi+\Delta \phi)-\alpha \Delta \phi$. The solution to capacity building is the maximum between the "no investment" strategy $\Delta \phi=0$ with payoff $\widehat{W}_{E}^{E}(\phi)$ and the "full investment strategy" with payoff $\widehat{W}_{E}^{E}(1)-\alpha(1-\phi)$. No investment in state capacity is then preferred by the elite when $\widehat{W}_{E}^{E}(\phi)>\widehat{W}_{E}^{E}(1)-\alpha(1-\phi)$ or equivalently when $\frac{\widehat{W}_{E}^{E}(1)-\widehat{W}_{E}^{E}(\phi)}{1-\phi}<\alpha$. The convexity property of the elite function $\widehat{W}_{E}^{E}(\phi)$ ensures that this will be the case when the initial state capacity value $\phi$ is small enough (ie. $\left.\phi<\phi_{\alpha}\right)^{10}$. It is only if some state capacity already exists (ie. $\phi \geq \phi_{\alpha}$ ) that the Elite may have an incentive to develop it further so as to maximize the rent it can extract through taxing workers. In other words, it is the 'rent-seeking motivation' rather than the 'business motivation' that leads the elite to develop state capacity in the present framework.

This conclusion might not hold anymore if the proceeds of the tax could be used by the elite in a public good that would increase the returns to its asset, as it would be the case, for instance, with some types of infrastructure. As a matter of fact, such an assumption is probably needed if the present model is to fit the case of autocratic developing countries which centered their development strategies on manufacturing.

\section{$3 \quad$ State capacity under power shifting}

So far we assumed that the elite could not lose political control. In reality losing political power is often one of the major concerns of elite groups. The important point here is that such event may not be independent from the redistribution operated by the elite while in power. Also, the consequences of power shifting for the elite may well depend on the state capacity it would transmit to its

\footnotetext{
${ }^{10}$ Formally $\phi_{\alpha}$ is the solution of $\frac{\widehat{W}_{E}^{E}(1)-\widehat{W}_{E}^{E}(\phi)}{1-\phi}=\alpha$ which exists as soon as $\widehat{W}_{E}^{E}(1)-$ $\widehat{W}_{E}^{E}(0)<\alpha$ as assumed in figure 2 .
} 
successor in power. Hence, beyond the logic of "market revenue" generation and "rent extraction" considered so far, another determinant of the redistribution imposed by the elite relates to political control. In this section, we discuss the implications of this additional motive for equilibrium policies and state capacity building.

Consider for instance the possibility for the working Class to revolt and overthrow the elite. To simplify considerably the analysis and in order to stick to a simple static framework, consider the following two stage game:

- In stage 1, the elite is in power. It decides about its tax rate on the working class $\tau_{L}$ (or alternatively the allocation of labor $L$ in the formal sector) and commits to that policy for the future, conditionally on revolts by the working class not being successful with probability $\pi$.

- In stage 2, if their revolt succeeds, the working Class takes power and implements their preferred redistributive policies; otherwise the elite stays in power and implements the policies chosen in stage 1 .

\subsection{Equilibrium redistribution under the working class regime}

Before considering the behavior of the elite while in power, we have to figure out what will happen in a new regime controlled by the working Class. In that regime, it is natural to assume that the working class will maximize the average payoff of its members. As in the elite case, that average payoff is derived from two sources. First there is a "market income" reflecting the labor income obtained by the working class in the economy. Second, there is the "rent income" that comes from taxation on the elite's assets. Following the same logic as in the previous section with the elite, the working class will choose a redistributive policy that tradeoffs the "market income" motive against the "rent-extraction" motive. ${ }^{11}$ The higher the level of state capacity $\phi$ inherited from the Elite, the larger the "rent extraction" motive for the Working Class, and the more it will actually extract from the elite. The equilibrium outcome under the working class rule provides therefore equilibrium payoffs $\widehat{W}_{L}^{L}(\phi)$ and $\widehat{W}_{E}^{L}(\phi)$ respectively for the working class and the elite, that depend on the level of state capacity $\phi$. Given that an increase in $\phi$ allows the working class to extract more rents from the elite, it follows naturally that $\widehat{W}_{L}^{L}(\phi)$ is non-decreasing in $\phi$, while $\widehat{W}_{E}^{L}(\phi)$ is non-increasing in $\phi$.

\subsection{Elite's behavior under power shifting}

We can consider now the taxation decision of the elite in the first stage, when there is a risk of power shifting.

\footnotetext{
${ }^{11}$ Nothe that this argument is based on the assumption that an overthrow of the Elite by the Working Class does not involve any redistribution of the productive asset $\bar{K}_{E}$. In effect, expropriation takes place after the overthrow through a tax on the return to the Elite's asset. Such assumptions could be justified if the asset owned jointly the asset $\bar{K}_{E}$ and the knowledge needed to combine it with labor for producing the numeraire good.
} 


\subsubsection{Exogenous probability of power shifting}

Let us assume as a first step that the probability, $\pi$, that the elite will stay in power in stage 2 is exogenous. The objective of the elite then writes as

$$
\widetilde{W}_{E}(L)=\pi\left[G_{E}^{\prime}\left(\bar{K}_{E}, L\right) \bar{K}_{E}+\phi R\left(\bar{K}_{E}, L\right)\right]+(1-\pi)\left[\widehat{W}_{E}^{L}(\phi)\right]
$$

where $\widetilde{W}_{E}(L)$ is the expected value of the elite's payoff. With probability $\pi$ the elite stays in power and gets a payoff derived from its "market income" $G_{E}^{\prime}\left(\bar{K}_{E}, L\right) \bar{K}_{E}$ and its " rent income" $\phi R\left(\bar{K}_{E}, L\right)$ extracted from workers. With probability $1-\pi$ however the elite looses power and receives its equilibrium payoff $\widehat{W}_{E}^{L}(\phi)$ under political control by the working class.

Clearly, the decision about formal employment (or equivalently labor taxation) taken by the elite is the same as when the probability of losing power was ignored. Therefore properties i) and ii) discussed in section 2.4 remain valid.

An important difference though is for the marginal incentives of the elite to invest in state capacity building. There is now the possibility for the maximum payoff of the elite $\widehat{W}_{E}^{p}(\phi)=\operatorname{Max}_{L \in\left[0, L_{0}\right]} \widetilde{W}_{E}(L)$ to be non increasing in the level of state capacity $\phi$. Indeed, the first part of (5) -which corresponds to $\widehat{W}_{E}^{E}(\phi)$ above- is an increasing function of state capacity, whereas the second part, $\widehat{W}_{E}^{L}(\phi)$, is decreasing. The net effect of an increase in state capacity depends therefore on the relative strength of these two parts. Given that $\widehat{W}_{E}^{p}(\phi)=$ $\pi \widehat{W}_{E}^{E}(\phi)+(1-\pi) \widehat{W}_{E}^{L}(\phi)$, it follows immediately that whenever the probability to stay into power $\pi$ is small enough, the negative channel (through $\widehat{W}_{E}^{L}(\phi)$ ) outweights the positive channel (through $\widehat{W}_{E}^{E}(\phi)$ ). In that case the equilibrium payoff of the elite $\widehat{W}_{E}^{p}(\phi)$ is a decreasing function in state capacity.

Similarly, when $\phi \leq \phi_{0}$ and the elite does not tax workers, $\widehat{W}_{E}^{E}(\phi)$ is independent from $\phi$ and the only effect of state capacity goes through the negative channel (through $\left.\widehat{W}_{E}^{L}(\phi)\right)$. In such a case as well, the equilibrium payoff of the elite $\widehat{W}_{E}^{p}(\phi)$ is a decreasing function in state capacity.

The intuition behind these results is quite simple. First, in the presence of a significant probability of losing power, the elite prefers not to invest in state capacity because it might be used against itself by the working class in case it seizes power. Second, in the most extreme case where state capacity is already weak enough so that the elite does not tax labor, building up state capacity would only serve the working class when in power. Here again the threat of losing power decreases the elite incentives to invest in state capacity ${ }^{12}$.

\footnotetext{
${ }^{12}$ Besley and Persson (2007) obtain a similar result, although less extreme. In their framework, political instability reduces the incentives to invest in state capacity but does not necessarily reverse them.
} 


\subsubsection{Endogenous probability of power shifting}

Consider now the case where the probability $\pi$ of staying in power is endogenous and depends on the utility of the working class under the elite's rule. Various cases may be considered.

\section{- The "resource capacity" case.}

A first possibility is the fact that the probability $\pi$ is a decreasing function of the income of the political challenger - a higher level of income of the working class allows them to invest more in a successful overthrow (Acemoglu (2006)). In such a case, the elite is even more radical than in the preceding model without power shifting. Extracting rents from the working class not only generates some tax income but also weakens the workers' capacity to revolt, increasing thereby the probability of staying in power for the elite. Consequently the optimal tax rate on the Working class will be larger than without power shifting.

The incentives to invest in state capacity remain however ambiguous. As in the exogenous power shifting case, a non-zero probability of losing power reduces the benefits that the elite can draw from increasing state capacity, as that can be used by the working class if it ever gets into power.

\section{- The "incentives" case}

The alternative assumption of $\pi$ being increasing with the utility of the working class may also be justified. For instance, a reasonable specification for $\pi$ can be given by the following:

$$
\pi=\Pi\left[W_{L}-\left(\widehat{W}_{L}^{L}(\phi)-c\right)\right]
$$

In that expression, the probability of the elite staying in power depends on the relative loss for the working class to be under the rule of the elite instead of being in command of the economy. $\Pi($ ) is an increasing function in $[0,1]$, $W_{L}$ reflects the utility of the working class under the elite domination regime, $\widehat{W}_{L}^{L}(\phi)$ is the utility level of the working class when it is in power and $c$ is the cost of undertaking a revolt to overthrow the current elite.

This specification implicitly assumes that the binding constraint on power shifting for the elite indeed emanates from the "interest" of the working class to forment a revolution and not from its "resource capacity"to do $\mathrm{so}^{13}$. Note also that, as usual in the literature in political economy, this specification abstracts from issues of group formation, free riding and coordination that exist in political collective action.

\footnotetext{
${ }^{13}$ An alternative specification could combine both the "incentives" and "resource capacity" approaches by assuming that the "incentives" logic starts to matter only when the disposable income of the working class under the elite regime is larger than a minimum resource cost. We abstract from this for simplicity.
} 
The problem of the elite will be again to maximize its expected payoff

$$
\bar{W}_{E}=\pi W_{E}+(1-\pi) \widehat{W}_{E}^{L}(\phi)
$$

where $\pi$ is given by (6) and $W_{E}$ stands as before for the utility of the elite when in power. In general, the elite can use both redistributive instruments such as taxes and transfers and repressive instruments used to increase the cost $c$ of rebellion.

On top of the "business interest" and "rent extraction" motives, the elite may also want now to increase the probability to stay in power $\pi$ through two possible strategies. The first one is to increase the utility of the working class $W_{L}$ through reduced taxation or the provision of specific transfers. The second strategy is to increase the cost of rebellion $c$ through investments in violent repression. Both strategies however are costly as they reduce the amount of income that the elite can get for itself while in power. The solution for the elite reflects then these different tradeoffs. In particular, on top of the "business interest" logic, the "incentives" logic of rebellion adds up a limit to the "rent extraction" logic of the elite. The optimal elite redistributive policies will be therefore less biased against the working class than in the situation with exogenous (or no) threat of power shifting.

At the optimum, the payoff of the elite will have the following form:

$$
\widehat{W}_{E}^{p}(\phi)=\widehat{\pi}(\phi) \widehat{W}_{E}^{E d}(\phi)+(1-\widehat{\pi}(\phi)) \widehat{W}_{E}^{L}(\phi)
$$

It depends on state capacity $\phi$ through three channels. The first one is the optimal utility of the elite while in power $\widehat{W}_{E}^{E d}(\phi)$ (i.e. choosing optimal policies under an endogenous threat of rebellion). The second channel is the utility $\widehat{W}_{E}^{L}(\phi)$ obtained by the elite under the working class rule. Finally, the last term is the equilibrium probability $\widehat{\pi}(\phi)$ to stay in power (given the optimal policies chosen by the elite).

In terms of the incentives to invest in state capacity, endogenous power shifting generates some ambiguity again. First of all, an increase in state capacity $\phi$ tends to increase $\widehat{W}_{E}^{E d}(\phi)$ the optimal utility of the elite while in power. This corresponds to the positive effect of increasing state capacity without power shifting. Second, an increase in $\phi$ reduces the utility $\widehat{W}_{E}^{L}(\phi)$ of the elite under the working class rule. This term reflects the effect of a non-zero probability for the elite to lose power - as seen in the preceding case of an exogenous probability. Finally, an increase in $\phi$ reduces also the probability $\widehat{\pi}(\phi)$ for the elite to stay into power. As can be seen from (6), an increase in state capacity increases the utility level $\widehat{W}_{L}^{L}(\phi)$ that the working class can get while in power. This in turn stimulates the working class incentives to trigger a rebellion and consequently reduces the probability $\pi$ for the elite to keep political control. Making the probability of staying in power endogenous with the specification (6) thus adds a negative effect of state capacity on the equilibrium value of the elite's utility.

The conclusion of the analysis of the "incentives" case for endogenous power shifting is the fact that it unambiguously reduces the incentives for the elite to tax the working class. It is not only the threat of losing power that is responsible 
for this result - as seen in the preceding sub-section - but also the fact that this threat depends on the rent the elite extracts from the working class. The endogeneity of the threat to lose power is also blurring considerably the role played by state capacity. In particular it adds an additional element of ambiguity with respect to the incentives for the elite to invest in better tax institutions.

\section{The case of a purely political elite}

Several of the preceding results are governed by the fact that the elite has some "business interests" that are complementary to labor. Indeed, while taxing labor, the elite has to take into account the impact this will have on the return to its own asset. It is interesting to contrast this case of a 'business elite' with a case where this effect is absent, as if the elite were not actually operating in the economy, but only getting rents, as for instance with the exports of some natural resource with relatively negligible labor input and extraction costs, as can be observed in some autocratic African countries and, of course, in several elite-dominated oil exporting countries ${ }^{14}$. Such a case may be represented in the preceding framework by simply assuming separability between labor and the asset owned by the elite in the production function.

The important point is that the separability between the elite's assets and other inputs in the formal sector significantly affects the shape of its incentives to invest in state capacity. To see that and stick to our assumption of constant returns to scale in production, let us assume that the production function in the formal sector of the economy takes now the following linear form:

$$
G\left(\bar{K}_{E}, L\right)=\bar{K}_{E}+b L
$$

Using the same arguments as above, it can be seen that, in the absence of power shifting risk, the objective of the elite now writes:

$$
\operatorname{Max}_{L} \bar{K}_{E}+\phi \cdot\left(b-w^{S}(L)\right) \cdot L
$$

The solution of this problem (which essentially is the Laffer curve framework) always yields the Laffer curve maximizing level $L_{f}<L_{0}$ which is independent from state capacity $\phi$ - ignoring the indeterminate case where $\phi=0$.

The maximized value of the objective function of the elite now is

$$
\widehat{W}_{E}^{E}(\phi)=\bar{K}_{E}+\phi \cdot\left(b-w^{S}\left(L_{f}\right)\right) \cdot L_{f}
$$

which is a linear function of the state capacity $\phi$.

With respect to the incentives to invest in state capacity, this feature implies interesting differences between "business" and " political" elites. Indeed, assume again a constant marginal cost of expanding state capacity $\alpha$. Then a

\footnotetext{
${ }^{14}$ Of course, there are also examples where the natural resource that is exported is also consumed at home, as could be the case for major agricultural resource exporters such as Argentina or Brazil.
} 
"political" elite will do nothing if the cost $\alpha$ is higher than its marginal benefit $\left(b-w^{S}\left(L_{f}\right)\right) \cdot L_{f}$, or it will maximize state capacity if the opposite relationship holds. In contrast with "business elites", for political elites the incentives to invest in state capacity do not depend on the current level of state capacity ${ }^{15}$

\section{Introducing three groups: substituability and complementarities}

Obviously, the previous 2-class models are only able to capture some simplified features of actual political economy situations. For instance, it does not make very much sense to consider the case of a political elite facing only a class of undifferentiated workers. In actual economies rents would more likely to be extracted from a class of entrepreneurs, or perhaps skilled workers, with possible changes in the conclusions obtained above. Likewise, in the case of the business elite some properties derived above may well be specific to a 2-class model where the two factors are necessarily complements to each other.

In this section, we discuss the possibility of richer production structures within 3-class models allowing for possibilities of substituability across factors of production. As it turns out substituability affect significantly the pattern of redistributive policies and how it interacts with the level of state capacity of the economy.

Consider therefore the following economy composed of three groups of agents: elite $E$, middle class $M$, and workers $L$. Each member of a particular group owns some asset that contributes to production. More specifically, the elite $E$ has $\bar{K}_{E}$ members, each one owning one unit of a specific asset $K_{E}$. Similarly each member of class $M$ owns one unit of a specific asset $K_{M}$, the size of class $M$ being $\bar{K}_{M}$. Finally the working class $L$ has size $\bar{L}$, each worker owning one unit of labor.

\section{- Production}

Now the numeraire good in the formal sector is produced with a standard neoclassical constant-return-to-scale concave technology $Q=G\left(K_{E}, K_{M}, L\right)$ using the two assets $K_{E}$ and $K_{M}$ of class $E, M$, and labor $L$. The gross returns to the different factors are given by the partial derivatives: $G_{E}^{\prime}, G_{M}^{\prime}$, and $G_{L}^{\prime} \cdot{ }^{16}$ Of special importance now will be the degree of complementarity versus substituability between the different factors. Specifically we will differentiate our discussion according to the sign of the cross derivatives $G_{E M}^{\prime \prime}, G_{E L}^{\prime \prime}$, and $G_{M L}^{\prime \prime}$.

\footnotetext{
${ }^{15}$ This conclusion can be shown to hold also for the case with power shifting when it is exogenous. With endogenous power shifting however, the conclusions for the Elite incentives to invest in state capacity remain ambiguous (see Bourguignon and Verdier 2009).

${ }^{16}$ Unless necessary, the arguments, $K_{E}, K_{M}$, and $L$ of all these functions will be dropped in what follows.
} 
Recall first that the constant-return-to-scale assumption on $G()$ implies that the gross marginal returns $G_{E}^{\prime}, G_{M}^{\prime}$, and $G_{L}^{\prime}$ are homogenous of degree zero. Using that property, the following relationships necessarily hold between the cross derivatives

$$
\begin{aligned}
G_{E M}^{\prime \prime} K_{M}+G_{E L}^{\prime \prime} L & =-G_{E E}^{\prime \prime} K_{E}>0 \\
G_{E M}^{\prime \prime} K_{E}+G_{M L}^{\prime \prime} L & =-G_{M M}^{\prime \prime} K_{M}>0 \\
G_{E L}^{\prime \prime} K_{E}+G_{M L}^{\prime \prime} K_{M} & =-G_{L L}^{\prime \prime} L>0
\end{aligned}
$$

The complementarity/substituability between the three factors leads to some typology of archetype economies. It is represented in figure 3 ).

a) The "full complementarity business elite" economy:

The first case corresponds to an economy where the three factors $K_{E}, K_{M}$ and $L$ are all complements to each other (i.e. $G_{E M}^{\prime \prime}>0, G_{E L}^{\prime \prime}>0$ and $G_{M L}^{\prime \prime}>$ $0)$.

b) The "complementary business elite" economy:

In that case the elite asset $K_{E}$ is complement to the assets of the other classes $K_{M}$ and $L$. However $K_{M}$ and $L$ are substitutes to each other (i.e. $G_{M L}^{\prime \prime}<$ $0, G_{E L}^{\prime \prime}>0$ and $\left.G_{E M}^{\prime \prime}>0\right)$.

c) The "substitutive business elite" economy:

In that case the elite asset $K_{E}$ is complement to one factor and substitute to the other, while the two other factors are complementary to each other. Two alternative situations may occur. $K_{E}$ may be complement to $L$ and substitute to $K_{M}$ (i.e. $G_{E L}^{\prime \prime}>0$ and $G_{E M}^{\prime \prime}<0$, which implies $G_{M L}^{\prime \prime}>0$ ). Or $K_{E}$ may be complement to $K_{M}$ and substitute to $L$ (i.e. $G_{E M}^{\prime \prime}>0$ and $G_{E L}^{\prime \prime}<0$ which also implies $\left.G_{M L}^{\prime \prime}>0\right)$

Note that the case of the pure political rent-seeking elite would correspond to the situation where the production function is separable in $K_{E}$ on the one hand and $\left(K_{M}, L\right)$ on the other. As this case is not fundamentally different from the analysis above in a 2-class/2-factor setting, it will be ignored here, so that the analysis that follows fits better the case of autocratic countries with a sizable manufacturing sector than natural resource exporters.

An illustration of the various situations listed above for a business elite is provided by the case where the middle class asset is skilled labor whereas the "working class", $L$, is endowed with unskilled labor and the elite with physical capital. Interestingly enough, it turns out that all the three main cases listed above are extensively used the economic literature.

The "full complementarity" case a) would correspond to assuming something like a Cobb-Douglas production function as in the empirical endogenous growth literature - for instance Mankiw et al. (1992). The "complementarity" case b) would refer to economies where it can be assumed that skilled and unskilled labor are highly substitutable, both of them being complementary to capital. 
Production functions with a CES function defined on the two labor inputs, which is itself nested within a Cobb-Douglas function with physical capital as the other input would correspond to that case - see for instance Caselli and Coleman (2006). Finally, the "substitutive" case c) would refer to economies endowed with the so-called "capital-skill complementarity" property - see for instance Krussell et al. (2000). In that case, a CES production function defined on capital and unskilled labor is nested into a Cobb-Douglas production function with skilled labor as the other argument.

A typical case of substitutability that fits case c) is the limit situation when the assets of the middle class and the elite are strictly identical. This would typically be the case when the elite is in fact part of the business community and competes, in some sense, with the other entrepreneurial classes to get a higher return on its own wealth. Conversely, the "complementarity" cases a) and b) may correspond to situations when physical capital - owned by the elite - and human capital - owned by some middle-class - are complementary. Some pre-democratic developing countries with large GDP shares of manufacturing and modern services production might fall in that category.

We will now see that the particular economic structures described by cases a), b), c) have important consequences for the optimal redistributive policies chosen by the elite and the way policies are affected by increased state capacity $\phi$.

As before, we assume that the numeraire good can be produced by members of the middle class $M$ and workers $L$ in an informal/subsistence sector that escapes taxation. This assumption implies the existence of inverse factor supply functions for labor $L$ and the middle class asset $K_{M}$ in the formal economy. Let denote these by $w=w^{S}(L)$ for labor and by $r_{M}=r^{S}\left(K_{M}\right)$ for $K_{M} \cdot w^{S}($.$) and$ $r^{S}($.$) are increasing functions with w^{S}(0)=0$ and $r^{S}(0)=0$.

As in section 2, we consider that the elite members can only produce in the formal sector and therefore that the supply of their asset is perfectly inelastic at $\bar{K}_{E}$.

\section{- Taxation}

We allow for income taxation of both the middle class and workers. More precisely, let $\tau_{i} \in[0,1]$ be the tax rate on the return to the assets owned by class $i \in(M, L)$. The " rent income" that the elite can extract from the economy can be written as $^{17}$ :

$$
T=\phi\left[\tau_{M} G_{M}^{\prime} K_{M}+\tau_{L} G_{L}^{\prime} L\right]
$$

\section{- Economic Equilibrium}

The demand for each specific factor of group $i \in(M, L)$ is given by the competitive equilibrium conditions:

$$
\left(1-\tau_{M}\right) G_{M}^{\prime}=r_{M} \text { and }\left(1-\tau_{L}\right) G_{L}^{\prime}=w
$$

${ }^{17}$ As previously, lump-sum taxation of the non elite income is excluded. 
The factor market equilibrium conditions for the middle class and workers write therefore $\operatorname{as}^{18}$ :

$$
\left(1-\tau_{M}\right) G_{M}^{\prime}=r^{S}\left(K_{M}\right) \text { and }\left(1-\tau_{L}\right) G_{L}^{\prime}=w^{S}(L)
$$

The solution of (8) gives the equilibrium allocations $K_{M}=K_{M}\left(\tau_{M} ; \tau_{L}\right)$ and $L=L\left(\tau_{M}, \tau_{L}\right)$ with a univoque correspondence between the equilibrium levels of assets $K_{M}$ and $L$ and the tax rates $\tau_{M}$ and $\tau_{L}$. The equilibrium elite asset return in the economy is then obtained as $r_{E}=G_{E}^{\prime}\left(\bar{K}_{E} ; K_{M}, L\right)$. Given a set of policies $\left(\tau_{M} ; \tau_{L}\right) \in[0,1]^{2}$, it is useful to characterize the set $A$ of implementable allocations of assets such that:

$$
K_{M}=K_{M}\left(\tau_{M} ; \tau_{L}\right) \text { and } L=L\left(\tau_{M}, \tau_{L}\right) \text { for } \quad\left(\tau_{M} ; \tau_{L}\right) \in[0,1]^{2}
$$

In terms of the quantities $K_{M}, L$ this can be formally described by :

$$
A=\left\{\begin{array}{c}
\left(K_{M}, L\right) \mid\left(K_{M}, L\right) \geq 0 ; G_{M}^{\prime}\left(\bar{K}_{E} ; K_{M}, L\right)-r^{S}\left(K_{M}\right) \geq 0 ; \\
\text { and } G^{\prime}{ }_{L}\left(\bar{K}_{E} ; K_{M}, L\right)-w^{S}(L) \geq 0
\end{array}\right\}
$$

\section{- The problem of the elite}

In this section, we concentrate on the situation where there is no threat of power shifting ${ }^{19}$. The objective function of the elite is then given by:

$$
W_{E}=G_{E}^{\prime} \bar{K}_{E}+\phi\left[\tau_{M} G_{M}^{\prime} K_{M}+\tau_{L} G^{\prime}{ }_{L} L\right]
$$

Taking into account the equilibrium conditions (8), one can write the maximization problem of the elite in terms of allocations $\left(L ; K_{M}\right)$ as:

$$
\underset{\left(K_{M}, L\right) \in A}{M a x} \widehat{W}_{E}\left(K_{M}, L, \phi\right)=G_{E}^{\prime}\left(\bar{K}_{E}, K_{M}, L\right) \bar{K}_{E}+\phi R\left(K_{M}, L\right)
$$

with

$$
R\left(K_{M}, L\right)=\left[G_{M}^{\prime}\left(\bar{K}_{E}, K_{M}, L\right)-r^{S}\left(K_{M}\right)\right] K_{M}+\left[G_{L}^{\prime}\left(\bar{K}_{E}, K_{M}, L\right)-w^{S}(L)\right] L
$$

Two elements are to be noted. First, as before the income of the elite comes from two sources: the "market income" $G_{E}^{\prime}\left(\bar{K}_{E}, K_{M}, L\right) \bar{K}_{E}$ and the "rent income" $\phi R\left(K_{M}, L\right)$ where $R\left(K_{M}, L\right)$ is the tax proceeds on factors $L$ and $K_{M}$. Second, the quantities $\left(L, K_{M}\right)$ are to be chosen within the set of implementable allocations $A$, reflecting simply the fact that the asset allocation $\left(K_{M} ; L\right)$ has to be implementable under a tax policy $\left(\tau_{M}, \tau_{L}\right) \in[0,1]^{2}$.

\footnotetext{
${ }^{18}$ We make the usual boundary assumptions that ensure that (8) has a unique interior solution $K_{M} \in\left[0, \bar{K}_{M}[\right.$ and $L \in[0, \bar{L}[$

${ }^{19}$ The power shifting model analyzed above becomes much more complex in this case because of the need to model the coalition behavior and then, possibly, the power struggle between the Middle Class and the Working Class in case the Elite is overthrown.
} 
A full characterization of the elite problem is difficult ${ }^{20}$. Still, the role of substituability and complementarity relationships between the assets of the different classes can be illustrated by looking at the case of economies with weak state capacity levels (i.e. $\phi \approx 0$ ). In these economies, the elite's incentives for taxation are purely driven by the "market income" channel $G_{E}^{\prime}\left(\bar{K}_{E}, K_{M} L\right) \bar{K}_{E}$, reflecting therefore the importance of the productive interactions between the different factors of production in the economy. Again we may distinguish according to the different archetype economies.

\section{- a) The "full complementarity busines elite" economy}

In such an economy the marginal return of the elite asset $G_{K_{E}}^{\prime}$ is increasing with respect to the assets of the other two groups which are also complements to each other. In such a situation, the elite has a "business interest" to stimulate as much as possible the entry of $L$ and $K_{M}$ in the formal sector. This is done by choosing zero taxes (ie. $\left(\tau_{M}=\tau_{L}=0\right)$ on these assets. ${ }^{21}$. The intuition is exactly similar to that of result 1 . Indeed it reflects again the conflict between the "market income" and the "business" interests of the elite. Given the full complementarity of the elite's assets with the assets of the other two groups, the "market income" of the elite would be maximized with a maximum value of formal labor $L^{0}$ and middle class asset $K_{M}^{0}$ (ie. a zero tax on labor and middle class income). At the same time though, the elite could also extract rents from workers and the middle class through taxation. With weak levels of state capacity (i.e. $\phi \approx 0$ ), the "rent extraction" motive is not strong enough to induce the elite to tax the economy. The elite would get too little from rent-seeking in comparison with what it loses on the return of its asset and the optimal tax rates therefore are zero.

\section{- b) The "complementary business elite" economy}

In that case, the elite asset $K_{E}$ is complement to the assets of the other classes $K_{M}$ and $L$. However $K_{M}$ and $L$ are substitutes to each other. Again, the direct "business interest" drives the elite to choose no taxation inducing the maximum levels of $L$ and $K_{M}$ in the formal sector. The substituability between $K_{M}$ and $L$ creates however a difference with the full complementarity economy. Indeed taxing now one factor increases the marginal return of the second factor, stimulating its entry in the formal sector of the economy.This in turn benefits elite members as it increases the return of their own assets $\bar{K}_{E}$. The downside of such a policy however is a reduced supply of the taxed factor, which is also complementary to the elite's assets. When the complementarity between the elite assets and the other two factors is relatively balanced, the cost of taxing

\footnotetext{
${ }^{20}$ See Bourguignon and Verdier (2009) for a geometric characterization.

${ }^{21}\left(K_{M}, L\right)$ then is $\left(K_{M}^{0}, L^{0}\right)$, the allocation in the competitive equilibrium with no taxation, as given by the solution of:

$$
G_{M}^{\prime}\left(\bar{K}_{E}, K_{M}, L\right)=r^{S}\left(K_{M}\right) \text { and } G_{L}^{\prime}\left(\bar{K}_{E}, K_{M}, L\right)=w^{S}(L)
$$
}


one factor is not worth paying to stimulate entry of the other factor. In such a case the elite chooses not to tax the economy.

When however the elite's asset is strongly complementary to one factor and much less so to the other (i.e. a case of "unbalanced complementarity"), then it is worth for the elite to tax the less complementary factor in order to benefit from the increased supply of the more complementary one. This situation corresponds to an interesting case of factor price manipulation in which the elite maximizes the returns of its assets, exploiting the substituability that exists between the other factors in the economy. Importantly, this case of factor price manipulation occurs, not because one of the assets of the two classes $M$ and $L$ is a direct substitute to the asset of the "business elite" (as will be the case for the substitutive business elite" economy, see below) but because these assets are direct substitute to each other. The elite may then find profitable to exploit this substituability that affects indirectly its own return.

\section{- c) The "substitutive business elite" economy}

In the last archetype economy, the "substitutive business elite" economy, the elite asset $K_{E}$ is substitute to one factor and complement to the other. Note as well that in such a situation, the two other factors $K_{M}$ and $L$ are necessarily complements.

To fix ideas consider for instance the case in which the elite asset is a substitute to $K_{M}$ and a complement to $L{ }^{22}$. In such a situation, in order to maximize the return on its assets, the elite would like to have as little as possible of the substitute factor $K_{M}$. On the other hand, it would like to have as much as possible of the complement factor $L$. Given however the fact that $K_{M}$ and $L$ are complements, these logics enter in conflict. Indeed, taxing the substitute factor $K_{M}$ leads to a reduction of the labor wage $w$ and therefore to a reduced amount of the complement labor $L$ in the formal economy. This in turn reduces the return of the elite asset. The "business interest" motivation induces therefore a tradeoff for the elite in terms of its taxing policy.

Two cases may then intuitively arise. When the substituability relationship with $K_{M}$ is strong enough (i.e a situation of "strong substituability"), the strategy to tax that substitute factor is profitable. The elite will then impose a positive tax rate on that factor and a zero tax rate on the complement factor. In the extreme, when there is very strong substituability with $K_{M}$, it may even be profitable to the elite to impose a truly prohibitive tax on the middle class $M$ prohibting its entry into the formal sector of the economy $\left(K_{M}=0\right)$.

Conversely, when the substituability relationship with $K_{M}$ is weak (i.e. a situation of "weak substituability"), then the strategy to tax the substitute factor is too costly, given the indirect consequences on the complement factor $L$. In that case, the elite will not tax the substitute factor and again implement a zero tax regime on both $K_{M}$ and $L$.

Whether it gives rise to partial or complete taxation of the substituable factor $K_{M}$, the situation of a "strong substituability" is driven by a motivation

\footnotetext{
${ }^{22}$ The other case can be treated analogously.
} 
for factor price manipulation as found for instance in Acemoglu (2006). Indeed, the elite has no motive for rent extraction (as $\phi=0$ ). Nevertheless, it is taxing the substitute factor in order to increase the return of its own factor. In opposition with the 2-factor model analyzed above, this is a case where the elite does not tax to extract rents from the other factors of production but in its true business interest.

Interestingly, even with factor substituability between $\bar{K}_{E}$ and $K_{M}$, the case of "weak substituability" reflects the importance of multilateral and feedback relationships in a multi-factor world. Indeed, in that case the elite may choose the no-tax equilibrium, thus refraining from taxing the substitute factor $K_{M}$. This is so because $K_{M}$ is also complement to labor $L$ which is in turn complement to the elite assets $\bar{K}_{E}$. Hence, when these complementarity relationships are strong enough compared to the substituability effect, it does not pay to the elite to manipulate factor prices.

\section{- The effects of state capacity on redistributive policies}

How is the policy of the elite affected when state capacity $\phi$ increases? Clearly, an increase in $\phi$ increases for the elite the weight of the "rent income" channel $R\left(K_{M}, L\right)$ compared to the "market income" channel $G_{E}^{\prime}\left(\bar{K}_{E}, K_{M}, L\right) \bar{K}_{E}$. The logic of rent extraction is therefore strenghtened relative to the logic of factor price manipulation. Again the effects of this on the elite's incentives to tax the economy will depend on the underlying production structure.

In an economy where there are strong enough and balanced factor complementarities (i.e. the previous cases of a "full complementarity business elite", a" balanced complementary business elite" or a "weakly substitutive business elite"), the "market income" channel drives the elite to impose low tax rates on the factors owned by the other classes. An increase in state capacity $\phi$ brings back the elite's interest in rent extraction and therefore an incentive to impose some positive tax on at least one of the other classes' assets. In that case, higher state capacity leads to the elite to increase taxes on the economy.

In an economy with strong enough factor substituabilities (i.e. for instance the case of a "strongly substitutive business elite"), then the "market income" channel drives the elite to manipulate factor prices through its tax instruments. Indeed the elite will impose a positive tax rate (prohibitive when the direct substituability with the elite's assets is strong enough) on the substitute factor and a zero tax on the other factor. With a larger state capacity $\phi$, the rent extraction motive kicks in again and the elite is ready to tradeoff a bit less of factor price manipulation for a bit more of rent extraction.This implies increasing the tax base for rent extraction on the substitutive factor and to increase tax revenues on the complement factor. The elite therefore taxes less the substitute factor and more the complement factor than it would be doing with low state capacity.

Summarizing, the previous discussion suggests that with an increase in state capacity $\phi$, assets that are complements to the factor owned by the elite are likely to be more taxed and assets that are substitute likely be less taxed. 


\section{Conclusions}

In this paper, we have reviewed a rich set of situations reflecting the relationships between the structure of political power, the quality of institutions (i.e. state capacity), the structure of the economy and the level and structure of taxation as decided by elites. As emphasized by Acemoglu (2006), in such setting two logics confront themselves: the rent extraction motive and the factor price manipulation motive. Our analysis then suggests one basic conclusion with respect to the role of economic structures: economic complementarities tend to favor the rent extraction logic, while economic substitutabilities tend to favor the factor price manipulation logic.

When the economy exhibits wide enough complementarities across factors of production, state capacity naturally promotes the rent extraction motive, and an increase in state capacity is likely to induce increased taxes on the economy.

The converse is true when substitutability relationships across factors of production give rise to opportunities for factor price manipulation by the elite. This factor price manipulation may operate directly as in the case of the "substitutive business elite" economy. It may also operate indirectly as in the archetype "Complement Business elite" economy where the elite's assets are complement to the other two factors which are substitute themselves to each other. At the same time, though, the price manipulation motive can be mitigated by the other complementarities that exist in the economy and that may feedback on the return of the elite's assets.

When substituability relationships are strong enough compared to complementarities, even with weak state capacity the elite will tend to tax the substitute factor or the less complementary factor. In that case, stronger state capacity by promoting again the rent extraction logic at the expense of the factor price manipulation logic will induce the elite to tax less the "substitutive" factor and to tax more the "complementary" factor.

Our analysis also discusses the incentives for elites to invest in state capacity and points out the importance of power shifting considerations. Typically without threat of losing power, elites always have positive incentives to invest in state capacity and our discussion suggests that there are naturally increasing returns to scale in such investments. Power shifting considerations however mitigate or may even revert those incentives. As a matter of fact, in a world with political uncertainty, improving state capacity may turn out to be a two-edge sword. First, as emphasized by Besley and Persson (2008) it allows other groups to extract more rents on society whenever they get into power. Second, it may also stimulate those groups to strive more for political power. Both phenomena reduce the expected return that elites can derive from improving state capacity.

Obviously, our analysis left out a number of important and interesting issues on the role of elites in the development process. First of all, it must be kept in mind that the models analyzed in this paper are static. An important extension therefore would be to cover in more detail the dynamics of the whole economy and the joint dynamics of factor accumulation and state capacity building.

Another aspect relates to the concept of fiscal state capacity. A simple choice 
of representing fiscal capacity has been made in this paper so as to facilitate the analysis. Better micro-foundations of what is state capacity and how it interacts with the economy remains however an essential item on the research agenda. Important issues related to bureaucratic efficiency, corruption, public good provisions, law and security could be then usefully analyzed.

Also, we emphasize very much the fact that a change of political power reduces the incentive for the elite to build state capacity because of the "twoedge" sword effect that state capacity can be "used against them" if they find themselves out of power. It should be noticed however that this feature may only apply to specific dimensions of state capacity. Indeed, state capacity is multi-faceted and not just about building a tax base. As a matter of fact, state capacity also involves dimensions such as the establisment of "rule of law" institutions and the promotion of meritocratic and non patrimonial bureaucracy that can serve as commitment mechanisms to protect social groups from power abuse. In that case, investment in such dimensions of state capacity has a protective benefit that would especially serve those actually out of political power $^{23}$.

It is also important to note that our arguments have been simplified by focusing only on one type of taxes (assets taxes). Allowing for more types of taxes would also generate different incentives for the elite, especially if there is intra-elite heterogeneity, a feature that we have not considered.

Certainly, all these extensions must be investigated before establishing empirically testable hypotheses on the behavior of autocratic elites with respect to state capacity building. The analysis in this paper suggests though several interesting hypotheses. This is the case for instance for state capacity building taking place only when some minimum level of capacity is already installed, the opposition between the purely 'political' and the 'business' elite or, more generally, the idea that the relationship between taxation and state capacity depends on the productive structure of the economy, and in particular the complementarity or substitutability of the asset owned by the elite and those under the control of rival groups. Before proceeding along these lines, however, it is necessary to check whether such conclusions still hold when other possible uses of state capacity or the taxes it permits to levy are considered.

Adequately amended though, the models analyzed in this paper may help reflect on some policy issues. Political economy models are inherently unable to deliver policy messages since policies are endogenous. This is not the case of policies originating from outside the domestic economy, though. For instance, the present model could be extended to derive implications for the way in which Official Development Assistance (ODA or aid) is and should be delivered to an elite-dominated developing country. This could shed some light on issues such as the role of conditional aid for state capacity building or the relative merits of project aid versus budget aid in countries with weak institutional environments.

${ }^{23}$ We thank a referee for pointing out this specific aspect of state capacity. 


\section{References}

Acemoglu D. (2006) "A Simple Model of Inefficient Institutions", Scandinavian Journal of Economics 108(4), pp. 515-546

Acemoglu D. and J. Robinson (2005) "Economic Origins of Dictatorship and Democracy", Cambridge University Press

Acemoglu D. and J. Robinson (2006) "De Facto Political Power and Institutional Persistence", American Economic Association Papers and Proceedings 96(2), pp. 325-330.

Acemoglu D. and J. Robinson (2008), "Persistence of Power, Elites and Institutions", American Economic Review, 98(1), pp. 267-93

Acemoglu, D., S. Johnson and J. Robinson (2002), Reversal of Fortunes: Geography and Institutions in the Making of the Modern World Income Distribution, Quarterly Journal of Economics, 117, pp. 1231-1294.

Acemoglu F. and S. Johnson (2005), Unbundling Institutions, Journal of Political Economy, 113(5), pp. 949-995

Amsden, A. (2001), The Rise of "the Rest": Challenges to the West from Late-Industrializing Countries. Oxford University Press.

Besley T. and T. Persson (2008), "Wars and state capacity", Journal of the European Economic Association 6, pp. 522-530.

Besley T. and T. Persson (2009), "The Origins of State capacity: Property rights, Taxation, and Policy", American Economic Review 99, pp. 1218-1244

Bourguignon F. and T. Verdier (2009), "The Political Economy of State Capacity Building and Redistribution in Elite Dominated Societies" , PSE Mimeo.

Brezis E. and P. Temin (1999), Elites, Minorities and Economic Growth, Elsevier, Amsterdam.

Brezis E. and F. Crouzet (2006), "The Role of Higher Education Institutions: Recruitment of Elites and Economic Growth" in T. Eicher, ed. Institutions and Economic Growth, MIT Press, pp. 191-213.

Brezis E. (2010), Elites and Economic Outcomes" in S. Durlauf and L. Blume, eds. New Palgrave Dictionary of Economics,

Caselli, F. and W.J Coleman (2006), The World Technology Frontier, The American Economic Review, 96(3), pp. 399-422 
Collier, D. (1979), "Overview of the Bureaucratic-Authoritarian Model." In The New Authoritarianism in Latin America, edited by David Collier, pp. 1932. Princeton: Princeton University Press.

Djankov, S. C. McLiesh and R. Ramalho (2006), Regulation and Growth, Economic Letters, 92(3), pp. 395-401

Dollar, D.and Kraay A.(2003), "Institutions, trade, and growth : revisiting the evidence," Policy Research Working Paper Series 3004, The World Bank

Evans, P., Rueschemeyer D. , and T. Skocpol, (1985),. Bringing the State Back In. New York: Cambridge University Press.

Glaeser E., La Porta R., Lopez de Silanes F., and A. Schleifer (2004), "Do Institutions Cause Growth" Journal of Economic Growth, vol. 9(3), pp.271-303.

Hossain N., Moore M., Kalati N., Manor J. and E. Reis, (1999), Elites, Poverty and Development, Background Paper for the World Development Report 2000/1 on Poverty*

Knack, S. and P. Keefer (1995), Institutions and Economic Performance: Cross-Country Tests Using Alternative Institutional Measures", Economics and

Politics, 7(3), pp.207-227

Krussell, P. , L. Ohanian, JV. Rios-Rull and G.Violante (2000), Capital Skill Complementarity: and Inequality: a Macro-economic Analysis, Econometrica, 68(5), pp. 1029-1053

Mankiw, G., D. Romer and D. Weil (1992), A Contribution to the Theory of Economic Growth, Quarterly Journal of Economics, 107(2), pp. 407-437

O'Donnell G (1979), "Tensions in the Bureaucratic-Authoritarian State and the Question of Democracy." In The New Authoritarianism in Latin America, edited by David Collier, pp. 285-318. Princeton: Princeton University Press.

Olson O., N. Sarma and A.Swamy (2000), Governance and Growth, Public Choice, 102 (3-4), pp. 341-364.

Rodrik D., Subramanian A. and F. Trebbi (2004), "Institutions Rule: The Primacy of Institutions over Geography and Integration in Economic Development", Journal of Economic Growth, vol. 9, no.2, pp. 132-165

Vu T. (2007), State Formation and the Origins of Developmental States in South Korea and Indonesia, Studies in Comparative International Development ,Winter, vol. 41, $\mathrm{n}^{\circ} 4$, pp. 27-56.

Vu T. (2010), Studying the State through State Formation, World Politics 62 , no. 1, January, 148-75. 


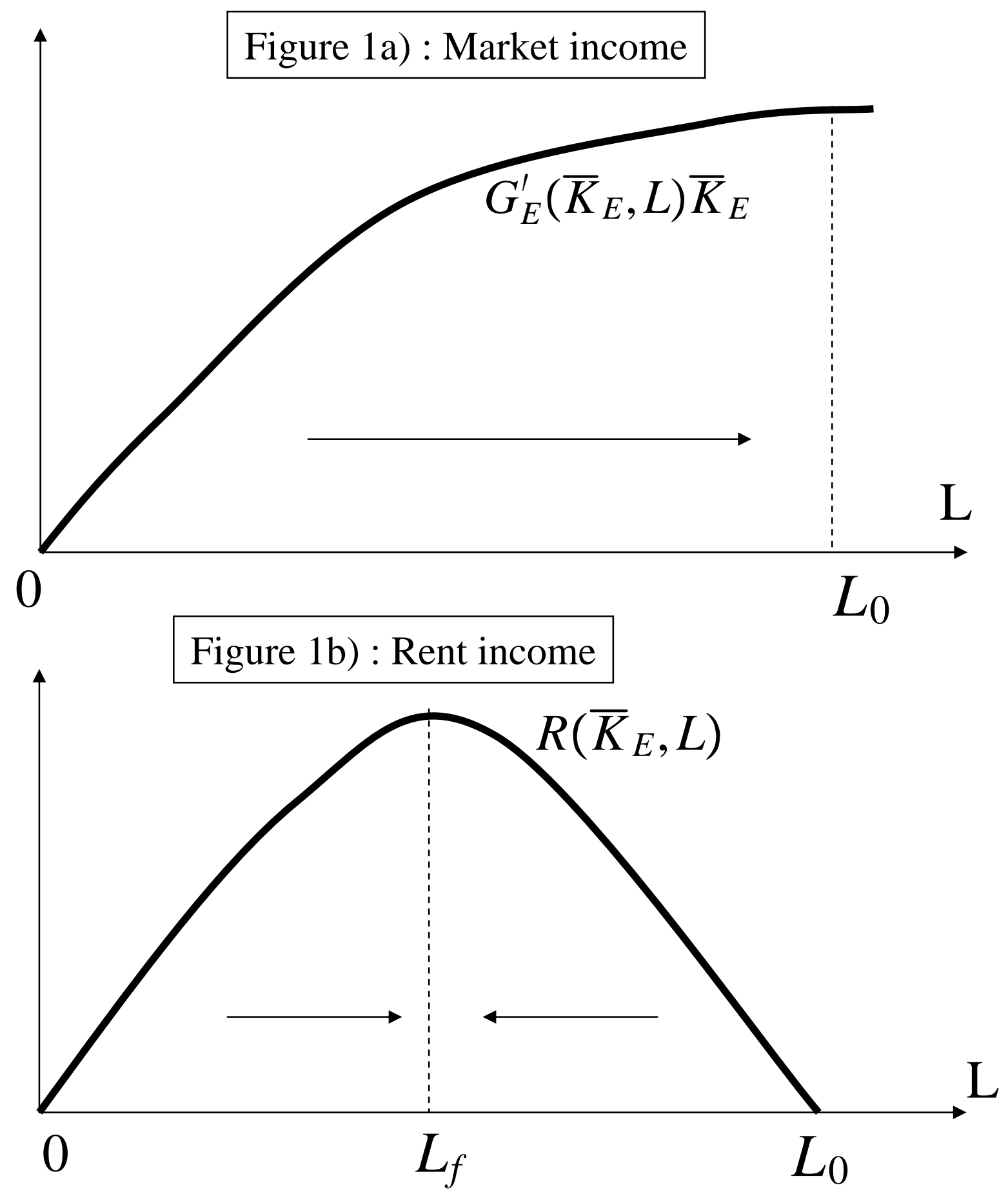




\section{Figure 2: Incentives for state capacity building}

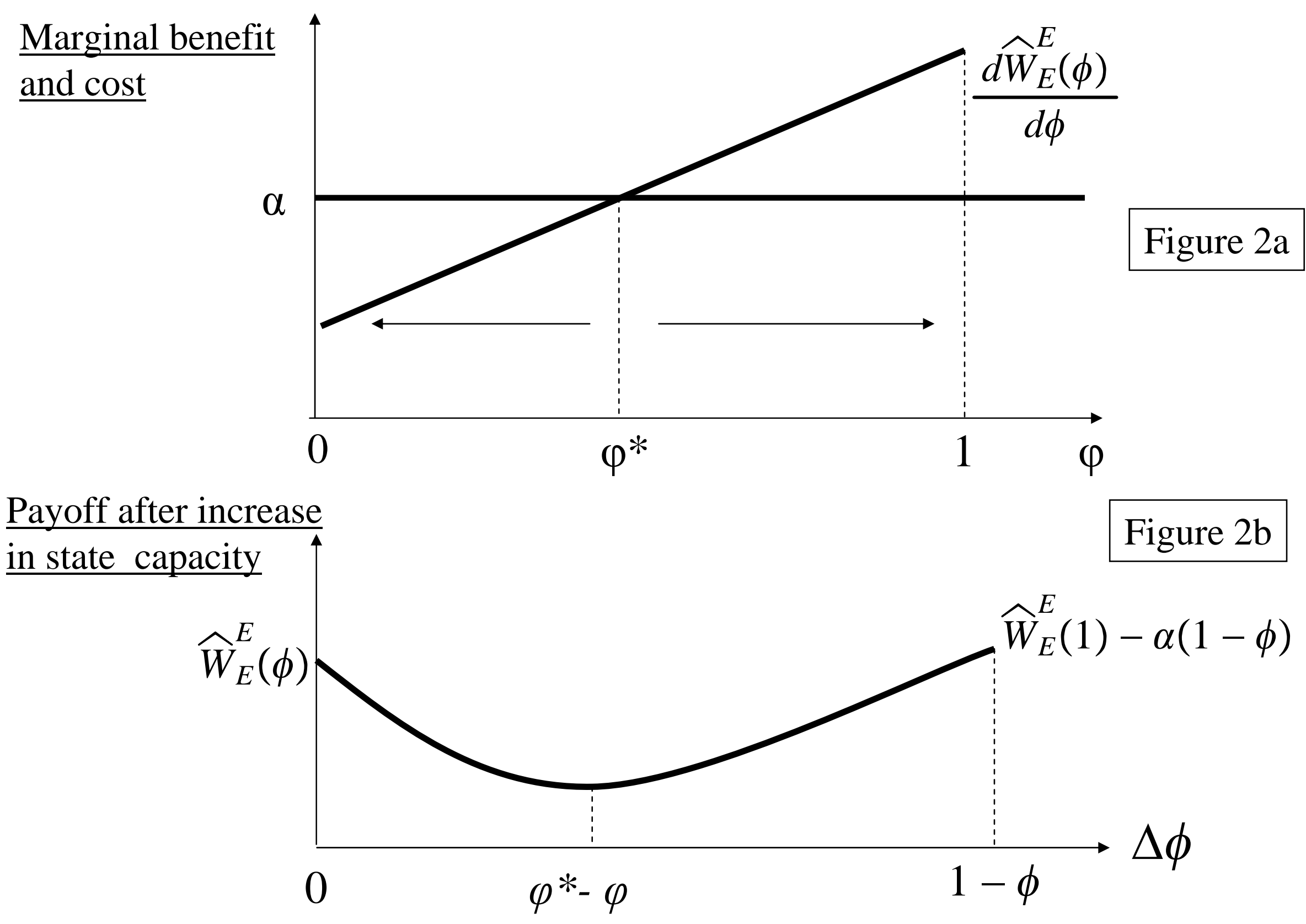


Figure 3: Archetype economies in a 3-Class Model

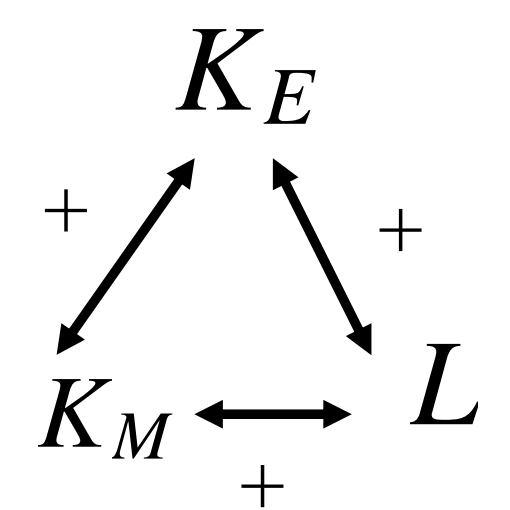

"Full

Complementarity Busines Elite"

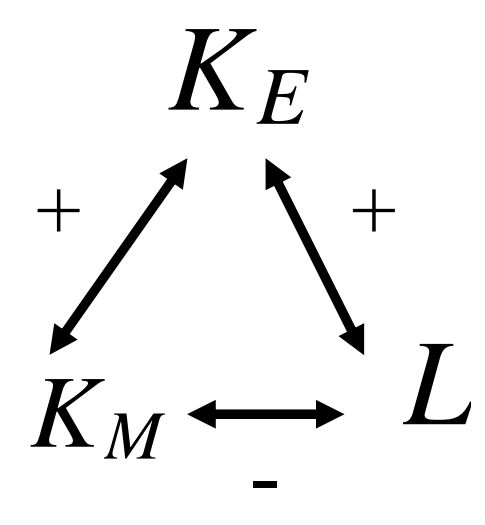

"Complementary Business Elite"
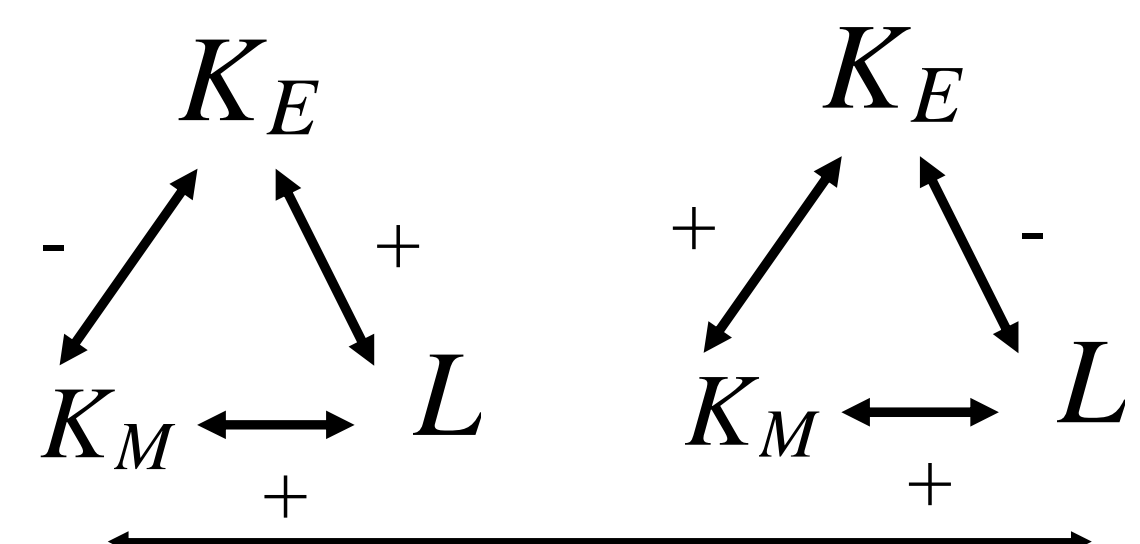

Substitutive Business Elite Economy 